Myrtia, no 34 (2019), 23-39

\title{
Los cimerios homéricos (Od. XI 11-19) y su presencia en la literatura grecolatina
}

[The Homeric Cimmerians (Od. XI 11-19) and their presence in Greek and Latin literature]

\author{
Jorge J. Linares Sánchez* \\ Universidad de Murcia
}

Resumen: $\begin{aligned} & \text { En el canto XI de la Odisea se incluye por primera vez una descripción del } \\ & \text { pueblo de los cimerios en el marco del relato de un viaje al mundo de los } \\ & \text { muertos. En este artículo realizamos un análisis comparativo del pasaje homérico } \\ & \text { y de diversos textos de la literatura grecolatina a fin de mostrar cómo, a partir de } \\ & \text { Homero, los cimerios se convirtieron en un elemento tradicional del tema. Para } \\ & \text { ello, explicamos las semejanzas y diferencias en cuanto a la presencia, } \\ & \text { denominación, características y ubicación de este pueblo mítico en cada texto con } \\ & \text { respecto al modelo homérico. }\end{aligned}$
Abstract: $\quad \begin{aligned} & \text { In canto Odyssey XI a description of the Cimmerian people is included for the } \\ & \text { first time as part of a journey to the netherworld's narrative. In this paper a } \\ & \text { comparative analysis of the Homeric passage and of various texts from Greek } \\ & \text { and Latin literature is carried out in order to show how, since Homer, the }\end{aligned}$
$\begin{aligned} & \text { Cimmerians became a traditional motive of this theme. For that purpose, the } \\ & \text { similarities and differences produced in terms of the presence, name, } \\ & \text { characteristics and location of this mythical town have been explained in each } \\ & \text { text regarding the Homeric model. }\end{aligned}$
$\begin{aligned} & \text { Palabras } \\ & \text { clave: }\end{aligned}$
$\begin{aligned} & \text { Keywords: Nékyia, cimerios, análisis comparativo, literatura grecolatina. } \\ & \text { Recepción: }\end{aligned}$ Odyssey, Nekyia, Cimmerians, comparative analysis, Greek and Latin Literature.
27/03/2019 Aceptación: 14/06/2019

El viaje al mundo de los muertos de Odiseo, la tradicionalmente denominada Nékyia, es uno de los episodios más complejos y apasionantes de la Odisea. El héroe, instado y ayudado por Circe, se dirige a la entrada del Hades, en los confines del Océano, para consultar al difunto Tiresias acerca de su regreso a Ítaca. Allí mantiene emotivos encuentros con momentos de gran intensidad dramática, como el desesperado intento por abrazar a su madre Anticlea o el airado silencio de Áyax. Estos y otros motivos fueron

* Dirección para correspondencia: Departamento de Filología Clásica. Facultad de Letras. Campus de la Merced. 30001 Murcia. E-mail: j1s12311@um.es 
actualizados y reelaborados en obras posteriores a lo largo de los siglos, pues la Nékyia fue y es un influyente modelo literario para la elaboración de viajes al más allá1.

En la Nékyia se combina el patrón literario de la nigromancia (evocación de los muertos) con el de la catábasis (descenso a los infiernos). Odiseo viaja a la entrada del Hades y hace salir por allí a los difuntos mediante un ritual. Sin embargo, también se describen almas en el interior del Hades, sin que se especifique si el héroe las observa desde fuera o ha accedido a las profundidades del Érebo ${ }^{2}$. El tema del viaje al mundo de los muertos implica el traslado del héroe a una región de ultratumba, normalmente una entrada al Hades, por la que este puede bien introducirse en el inframundo, o bien convocar a las almas para que acudan ante él.

Debido a esta ambientación de ultratumba, el canto XI de la Odisea gira en torno a la muchedumbre de almas atraída por el ritual nigromántico. Pero se menciona también a unos pobladores vivos, los cimerios, que habitan un territorio en el que la frontera entre la vida y la muerte queda desdibujada. Se trata de un pueblo de características singulares, descrito en los siguientes términos:

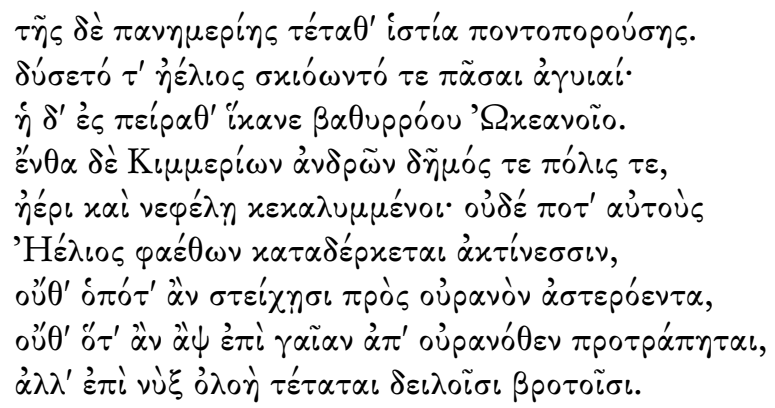

Durante todo el día la nave, desplegadas las velas, surcó el mar.

Se puso el sol y se oscurecían todos los caminos:

llegaba a los confines del Océano de profunda corriente.

Allí están el pueblo y la ciudad de los cimerios,

cubiertos de niebla y nube; nunca a ellos

el resplandeciente Helios los contempla con sus rayos,

ni cuando marcha al cielo estrellado,

ni cuando de nuevo vuelve a la tierra desde el cielo,

sino que una funesta noche se tiende sobre los míseros mortales. ${ }^{3}$

\footnotetext{
${ }^{1}$ Sobre esta cuestión puede consultarse mi tesis doctoral (Linares Sánchez 2017).

2 Véase, por ejemplo, Clark 1979, pp. 54, 74-78; Tsagarakis 2000, pp. 26-46 y 94-103; West 2014, pp. 123-124.

${ }^{3}$ Sigo el texto de la edición de P. von der Mühll $\left(1962^{3}\right)$. La traducción de los textos griegos y latinos es propia.
} 
Según el texto homérico, los cimerios son un pueblo mítico que habita una ciudad en el extremo del mundo, junto a la entrada del Hades. La niebla los rodea y están sumidos en la más absoluta oscuridad, pues Helios, el sol, no los ilumina en ningún momento de su recorrido cósmico, ni cuando asciende al firmamento al amanecer, ni cuando desciende al atardecer. Los cimerios no están situados en el interior del inframundo sino en sus inmediaciones, y queda de manifiesto que viven, pues se les

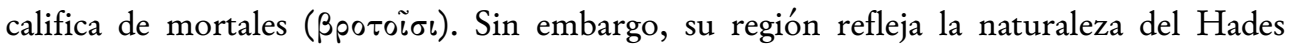
homérico, que se caracteriza por la niebla y la oscuridad, como los propios difuntos

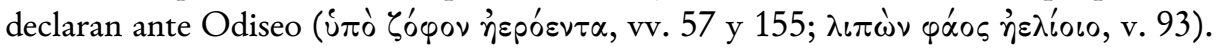

En el presente artículo examinamos la influencia de este pasaje en la literatura clásica a través del análisis literario y comparativo de diversos textos relacionados con el tema del viaje al mundo de los muertos. Analizaremos la pervivencia de los cimerios homéricos en la literatura grecolatina, estudiaremos las características homéricas que tienden a mantenerse o cambian, e indagaremos las causas de estas modificaciones. De esta manera, pretendemos mostrar cómo, a partir de su primera aparición en la Odisea, los cimerios se convirtieron en un elemento característico del tema en la tradición literaria grecolatina.

Para comenzar, conviene ofrecer algún apunte sobre el contexto literario en el que se compuso el pasaje. La descripción de las inmediaciones del inframundo forma parte del tema del viaje al mundo de los muertos. Este tema literario universal, de raigambre folclórica y presente en los cuentos populares ${ }^{4}$, entró a formar parte del repertorio épico, tanto en la epopeya griega como en la literatura oriental, dado que comparten ciertos rasgos literarios.

En la cultura egipcia el viaje al mundo de los muertos se asociaba al cambio de día y a la noche ${ }^{5}$. En numerosos conjuros del Libro de los muertos se menciona cómo Ra se dirige a occidente en su barca sagrada, lucha contra la gran serpiente Apofis, se introduce al atardecer en el inframundo a través del monte Manu y llena la oscura región de los muertos con su luz $z^{6}$. Puesto que es el dios del sol, su descenso y posterior ascenso marcan el ocaso y el amanecer. También se citan las siete puertas que deben atravesar los difuntos para acceder a la Duat, cada una custodiada por un portero, un guardián y un anunciador? ${ }^{7}$.

En Mesopotamia se asociaba el viaje al mundo de los muertos con el ciclo de la vegetación. Existen diferentes mitos que abordan este tema, como el descenso a los infiernos del difunto rey Urnamma, que entristece a su pueblo, el de la diosa Ishtar, cuya retención en el reino de los muertos provocó la infertilidad del mundo, o el de Nergal,

4 Thompson 1955, pp. 14-19.; Propp 1979; Hölscher 1991, pp. 99-116.

${ }^{5}$ Frenzel 1980 , p. 391.

${ }^{6}$ Léanse, e. g., los capítulos 7, 15, 39 o 108.

7 Capítulos 144 y 147, entre otros. 
Jorge J. Linares Sánchez

que se unió a Ereshkigal y se convirtió en rey del inframundo ${ }^{8}$. El viaje al mundo de los muertos es realizado por los dioses a través de una gran escalera que une el cielo y el reino de ultratumba. El rey Urnamma, sin embargo, debe recorrer un camino desolado, intransitable y embarrado. Para acceder al oscuro interior del Mundo Inferior es preciso atravesar siete puertas, custodiadas cada una por un guardián.

Dentro de la literatura oriental se ha investigado especialmente la relación de la antiquísima Epopeya de Gilgamés con la Odisea. En ambas obras se relata el peligroso viaje al más allá de sus protagonistas. A tenor de sus múltiples semejanzas ${ }^{9}$, se ha postulado que la fantástica aventura de Gilgamés pudo haber ejercido cierto influjo en la Nékyia homérica, aunque se trata de una cuestión controvertida ${ }^{10}$.

La aventura de Gilgamés no es propiamente un viaje al reino de los muertos, sino a los maravillosos confines del mundo. Consciente de su propia mortalidad por el fallecimiento de su amigo Enkidu, el rey de Uruk emprende este arriesgado periplo en busca de su antepasado Utnapishtim, que habría de ayudarle a obtener la inmortalidad. Sin embargo, hay diversos elementos, además de la motivación del episodio, que relacionan la aventura con el inframundo, como las Aguas de la Muerte y su barquero ${ }^{11}$.

En la primera etapa de este viaje Gilgamés llega a la montaña Masu, cuyos cimientos se hunden hasta el Hades (IX 41). La entrada a la montaña está custodiada por unos hombres-escorpión que «vigilan el sol tanto al amanecer como al anochecer» (IX 45). Los guardianes se sorprenden al ver allí al héroe, puesto que para llegar hay que franquear «muchos ríos cuyo cruce es peligroso» (IX 56). De manera similar, la difunta Anticlea preguntaba a su hijo Odiseo cómo había llegado a las puertas del Hades «pues en medio hay grandes ríos y temibles corrientes» (Od. XI 162). Finalmente, los guardianes permiten a Gilgamés adentrase en la montaña, aunque le han advertido que el camino está sumido en la oscuridad.

$$
\begin{aligned}
& \text { ša-pat ek-le-tùm-ma ul i[b-ba-áššši nu-ru] } \\
& \text { a-na a-șe-e d } \left.\left.{ }^{d} \text { šamšsi (utu }\right)^{\text {si i }} \text { i }\right\rceil-[\ldots . . .] \\
& \text { a-na e-reb ďšramši (utu } \left.)^{\text {si }} \ldots . . . .\right]
\end{aligned}
$$

\footnotetext{
${ }^{8}$ Puede leerse la traducción al castellano de estas y otras leyendas en Lara Peinado 2002.

${ }^{9}$ Por ejemplo, se considera que algunos personajes de la Nékyia presentan equivalencias con los del poema oriental: Circe con la diosa Siduri (que también se ha asociado a Calipso), Anticlea y Tiresias con Utnapishtim o Elpénor con Enkidu. Cf. Webster 1958, p. 83; Clark, 1979, pp. 27 y 32; West 2003 [1997], pp. 404-412 y 2014, p. 126.

10 Otros autores, como Tsagarakis (2000, p. 24) o Matijević (2015, p. 218), no consideran que estos paralelismos prueben la influencia literaria, sino que serían más bien producto del pensamiento universal y de unas condiciones culturales semejantes.

${ }^{11}$ Cf. Ponchia 2002, pp. 15-17; George 2003, pp. 499-500
} 
La oscuridad es intensa y no hay luz

Para la salida del sol [...]

Para la puesta del sol $[\ldots]^{12}$

Finalmente, en la Teogonía de Hesíodo, más cercana a los poemas homéricos, tanto geográfica como temporalmente, se describen varias moradas de divinidades situadas cerca de las mansiones de Hades. Allí residen Hipnos y Tánatos, hijos de la Noche:

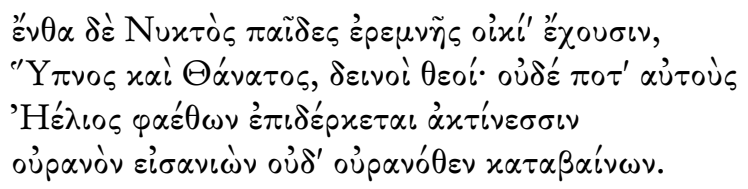

Allí tienen sus moradas los hijos de la negra Noche,

Hipnos y Tánatos, dioses terribles; nunca a ellos

el resplandeciente Helios los mira con sus rayos

al subir al cielo o al bajar del cielo. ${ }^{13}$

La morada de las divinidades del sueño y de la muerte carece de luz por la imposibilidad de Helios de alumbrarla con sus rayos durante su recorrido, igual que la ciudad de los cimerios. Es más, ambos pasajes presentan incluso afinidad textual, pues comparten versos similares $(O d \text {. XI 15-16 } \approx T h .759-760)^{14}$.

Podemos ver que en el contexto cultural de los poemas homéricos, en concreto en la literatura griega y oriental, el más allá se caracteriza por la oscuridad, que está muy estrechamente relacionada con la salida y la puesta del sol. En los textos orientales predominan grandes montañas como el lugar de acceso al inframundo y sus puertas están guardadas por seres monstruosos, pero no se menciona población alguna en sus inmediaciones. Hesíodo describe en el extremo del mundo, cerca del Hades, unas moradas habitadas por dioses. Solo Homero ha incluido en sus inmediaciones una población de humanos mortales que han construido allí una ciudad ${ }^{15}$. Nada se indica acerca de su función, pero

12 Traduzco al castellano a partir de la versión inglesa de George 2003.

${ }^{13}$ Hesiod, Theogony, ed. M.L. West, Oxonii, 1966.

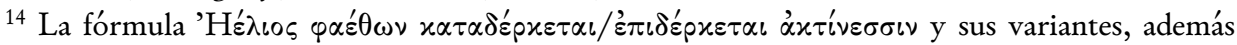
de en los citados pasajes, solo se reproducen, según la búsqueda realizada en el $T L G$, en las citas a Homero y Hesíodo de comentaristas y en textos de autores posteriores.

${ }^{15}$ No parece haber antecedentes literarios de la inclusión en las inmediaciones del inframundo de una ciudad poblada por mortales. El Motif-Index de Thompson en el apartado relativo al inframundo y al viaje al mundo de los muertos (F80-F109) no recoge nada al respecto (los cimerios son citados en F129.3). Lo único que encontramos es la existencia de casas (la casa de una bruja, de un ermitaño o una posada) en las inmediaciones de un más allá en sentido genérico, no el inframundo, dentro del cuento popular alemán. 
no parecen ser guardianes del Hades, pues Odiseo llega a la entrada del inframundo sin intervención alguna por su parte y Circe, cuando da al héroe las indicaciones pertinentes, no los menciona como un posible obstáculo. Se trata, pues, de una innovación homérica, que tendrá una relevante repercusión en la tradición posterior del tema.

Efectivamente, en los siglos sucesivos la gran importancia de los poemas homéricos en la cultura griega y latina facilitó que el viaje al mundo de los muertos de la Odisea fuera un episodio de referencia para las recreaciones del tema. De esta manera, algunos detalles de la Nékyia fueron adaptados a nuevos textos. El pueblo de los cimerios en particular es mencionado con frecuencia, conserva en gran medida la caracterización homérica y representa el lugar adecuado para la realización de evocaciones de las almas o descensos al inframundo. Sin embargo, también son relevantes los cambios producidos.

La literatura griega nos ha legado dos adaptaciones homodiegéticas de la Nékyia, es decir, versiones del episodio homérico que conservan la identidad de Odiseo como protagonista y los principales rasgos de los personajes y de la ambientación del texto original. Pero los cimerios también son mencionados o evocados en textos griegos sobre las aventuras de ultratumba de otros personajes.

La primera obra, Los evocadores de espíritus de Esquilo, pertenece al género teatral y recrea la experiencia nigromántica del itacense. A tenor de los fragmentos conservados, se desprende que esta versión, aunque fiel al argumento homérico ${ }^{16}$, aproxima la excepcional aventura a los usos de una ritualidad normalizada en un oráculo de los muertos. Para ello, los cimerios pierden su condición de habitantes de una ciudad mítica e inaccesible y se convierten en unos nigromantes profesionales encargados de un Nekyomanteion ${ }^{17}$. Esta modificación conlleva también divergencias en la participación de ambos grupos en sus respectivos textos. Mientras que en la Nékyia Odiseo no entra en contacto con los cimerios, por lo que estos quedan imbuidos en un aura de misterio, los psychagogoí de Esquilo forman parte del coro y ofrecen al héroe las instrucciones necesarias para la realización de la evocación ${ }^{18}$. A pesar de esta diferenciación, ambos grupos se definen por la región que habitan. Si los cimerios tienen su oscura ciudad junto a la entrada del Hades, los nigromantes se definen a sí mismos como «los de la laguna» (oi $\pi \varepsilon p i \lambda_{i}^{\prime} \mu \nu \alpha \nu, F r .273$ Radt), en referencia al lugar en el que confluyen los ríos del inframundo. Resulta difícil ofrecer más datos sobre esta laguna, debido al estado fragmentario del texto. Con frecuencia se ha identificado con el lago Averno, cerca de Cumas, o con el río Aqueronte en Tesprotia, donde había sendos oráculos de los muertos a los que podría adscribirse a los nigromantes de Esquilo. Ambos lugares han sido

${ }^{16}$ La obra dramatizaba al menos la llegada de Odiseo al mundo de los muertos, el sacrificio de evocación y el encuentro con el adivino Tiresias. Cf. Lucas de Dios 2008, pp. 665-667; Mikellidou 2016, p. 331.

17 Ogden 2001 p. 182; Mikellidou 2016, pp. 338.

${ }^{18}$ Estas instrucciones están basadas en las que Circe ofreciera al héroe en Odisea X. 
considerados como posible morada de los cimerios ${ }^{19}$. Sin embargo, tampoco podemos descartar por completo que se trate de un paraje fantástico en los confines del Océano ${ }^{20}$. En cualquier caso, los psychagogoí han erigido allí unos recintos sagrados $(\sigma \eta \eta \tilde{\omega} v)$. Se trata, por tanto, de un enclave habitado por humanos junto a una entrada al inframundo.

En las Ranas de Aristófanes, comedia representada por primera vez en el año 405 a. C., Dioniso desciende al inframundo para traer de vuelta a Eurípides, aunque al final opta por salvar precisamente a Esquilo. La naturaleza cómica de la obra subvierte la versión tradicional del mito y se sirve de referencias a otros viajes al mundo de los muertos, entre ellos la Nékyia, con una finalidad paródica. Cuando el dios llega ante la barca de Caronte, dispuesto a atravesar la laguna del Hades, el barquero cita varias regiones del inframundo, combinando nombres míticos con reelaboraciones paródicas:

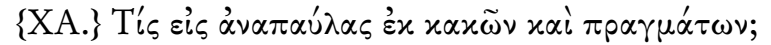

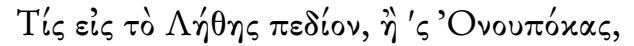

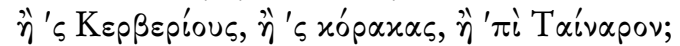

$$
\begin{aligned}
& \text { Ra. } 185-187
\end{aligned}
$$

\{CA.\} ¿Quién al lugar de descanso de males y cuitas? ¿Quién a la llanura del Olvido, o al Vellocino del Asno o a los Cerberios, o a los cuervos, o hacia el Ténaro? ${ }^{21}$

«Cerberios» es una deformación del nombre de los cimerios mediante su fusión con Cerbero ${ }^{22}$. Cabe destacar que Aristófanes los sitúa en el interior del inframundo y no en sus inmediaciones, como hiciera Homero. Se trata de una traslación del emplazamiento de los cimerios que se repetirá posteriormente.

La segunda versión homodiegética de la Nékyia que conservamos es de época helenística y fue escrita por Licofrón. En su Alejandra, un complejo poema con rasgos épicos, dramáticos y líricos, Casandra vaticina con un intrincado y enigmático lenguaje, característico del uso oracular, los sucesos posteriores a la caída de Troya. Entre ellos, destacan en el centro del poema las aventuras del Nóstos de Odiseo. Licofrón ofrece múltiples referencias geográficas eruditas acerca del lugar donde Odiseo evocó a los muertos: la

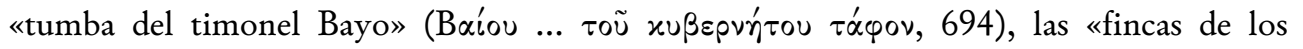

19 Cf. Clark 1979, p. 207; Ogden 2014, pp. 213-216. Entre los autores antiguos que abordan esta cuestión, sobre la que profundizaremos más adelante, están Tucídides (I 30.3 y 46. 3 ) y Estrabón (V 4. 5).

20 Sobre tal cuestión véase Mikellidou 2016, pp. 334-337 y las referencias bibliográficas que ofrece a pie de página.

${ }^{21}$ Aristophane, vols. 3-4, ed. V. Coulon - M. van Daele, Paris, $1977^{8}$ (= 1928).

22 Cf. Clark 1979, pp. 75-76; García López 1993, p. 89; Santamaría Álvarez 2015, p. 127; etc. Por otro lado, en las Aves (vv. 1553-1564) se hace un breve relato de una nigromancia en territorio de los Esciápodas («Sombrapies»), unos seres con grandes pies en forma de paraguas con los que se protegían del sol, por lo que han sido identificados con los cimerios (Ogden 2001, p. 97). 


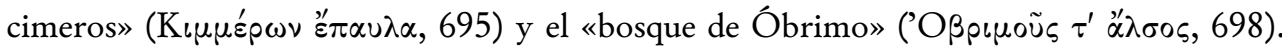
Tanto las fincas de los cimerios como el bosque de Óbrimo son detalles tomados del texto homérico. Las casas de los cimerios designan por sinécdoque la ciudad de estos moradores míticos y Óbrimo es un sobrenombre de Perséfone, junto a cuyo bosque Odiseo realizó la nigromancia. La mención de Bayo, timonel de Odiseo cuyo enterramiento en Bayas dio nombre a la localidad, nos indica que Licofrón sitúa la evocación de Odiseo en la zona de Cumas.

Los cimerios también aparecen en la novela griega, en concreto en Maravillas increíbles de allende Tule de Antonio Diógenes. Por desgracia, la obra se ha perdido, pero conservamos el resumen que de ella hizo el patriarca Focio en el S. IX. Entre las diversas peripecias características de este tipo de relatos, nos interesa la experiencia de ultratumba protagonizada por Dercílide:

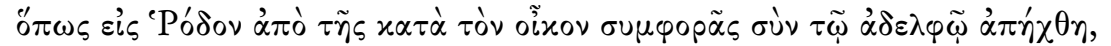

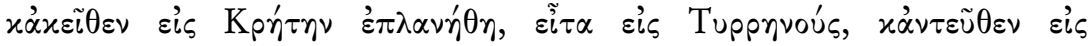

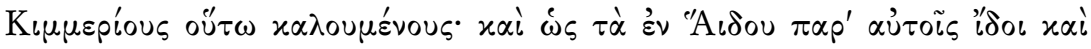

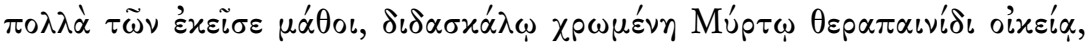

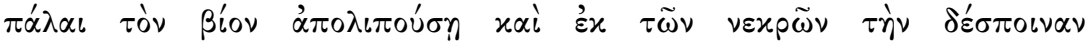
$\dot{\alpha} \nu \alpha \delta\llcorner\delta \alpha \sigma x \circ u ́ \sigma \eta$.

Focio, Bibl. codd. 166

De modo que fue llevada a Rodas con su hermano tras la desgracia en su casa, y de allí marchó errante a Creta, luego a los tirrenos, y de allí a los así llamados cimerios; y junto a ellos vio las cosas del Hades y aprendió muchas cosas de las de allí, sirviéndose como maestra de Mirto, su esclava personal, que había abandonado la vida hacía tiempo e instruyó de entre los muertos a su señora. ${ }^{23}$

Debido a la brevedad e imprecisión del texto es difícil saber si estamos ante una evocación realizada en territorio cimerio, ante un descenso o se mantuvo la ambigüedad de la Nékyia homérica. Tampoco podemos saber si había alguna descripción de la ciudad y en qué términos, pues el resumen de Focio nada dice al respecto. En cuanto a su localización, aunque la novela combina emplazamientos reales y ficticios, la travesía de Dercílide transcurre aquí dentro de la geografía histórica del Mediterráneo. Antes de

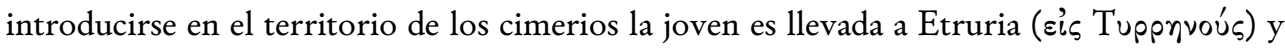

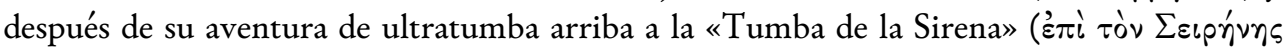
... $\tau \dot{\alpha}(\varphi \circ v)$, en Nápoles, por lo que los cimerios quedan situados en la zona de Campania, posiblemente cerca de Cumas ${ }^{24}$, como en la Alejandra de Licofrón.

${ }^{23}$ Photius, Bibliothèque, vol. 1, ed. R. Henry, Paris, 1959.

${ }^{24}$ Cf. Brioso 2002, p. 79. 
La literatura latina asimiló el bagaje literario de Grecia, por lo que la Odisea fue una de las principales obras de referencia entre los escritores romanos. La Nékyia es reproducida en comentarios y epítomes, e incluso algún texto literario, como el «Panegírico de Mesala», reelabora el episodio homérico. El texto se ha conservado en el Corpus Tibullianum y fue escrito seguramente por un joven poeta de este círculo, que presenta a Odiseo como modelo a fin de alabar a Mesala, nombrado cónsul recientemente. El poeta ofrece un breve resumen de las aventuras de Odiseo y entre ellas incluye la Nékyia, relatada en tan solo cinco versos, de los que tres están dedicados a los cimerios. La descripción de su ciudad sirve para ambientar el lugar de la evocación.

Cimmerion etiam obscuras accessit ad arcis, Quis numquam candente dies apparuit ortu, Seu supra terras Phoebus seu curreret infra.

Tib. III 7. 64-66

También llegó a las oscuras fortalezas de los cimerios a los que nunca se mostró el día con radiante amanecer, corriera Febo sobre las tierras o por debajo. ${ }^{25}$

Se mantienen los detalles homéricos del pasaje; como en $O d$. XI 14-19 se enfatiza la imposibilidad del sol, aquí personificado en Febo, de iluminar a los cimerios en su recorrido. Pero se especifica que su morada es una «ciudadela fortificada» (Cimmerion ... arcis).

En Metamorfosis XI Ovidio relata el viaje de la mensajera Iris a la morada del Sueño, cerca de la cual viven los cimerios:

Est prope Cimmerios longo spelunca recessu, mons cavus, ignavi domus et penetralia Somni: quo numquam radiis oriens mediusve cadensve Phoebus adire potest; nebulae caligine mixtae exhalantur humo dubiaeque crepuscula lucis. non vigil ales ibi cristati cantibus oris evocat Auroram, nec voce silentia rumpunt sollicitive canes canibusve sagacior anser; non fera, non pecudes, non moti flamine rami humanaeve sonum reddunt convicia linguae.

Hay cerca de los cimerios una gruta en un lugar muy apartado, un monte hueco, hogar y santuario del perezoso Sueño, donde nunca con sus rayos al salir o en lo alto o al caer puede Febo llegar; nubes mezcladas con niebla

${ }^{25}$ Albii Tibulli Aliorumque Carmina, ed. G. Luck, Stutgardiae, 1988. 
son exhaladas por la tierra y un crepúsculo de incierta luz.

Allí ni la atenta ave de encrestada cabeza evoca

a la Aurora con cantos, ni con su voz rompen los silencios

los agitados perros o el ganso más sagaz que los perros;

ni fieras, ni ganado, ni ramas movidas por el viento

o el alboroto de la lengua humana producen sonido. ${ }^{26}$

Ovidio realiza una importante innovación respecto al texto homérico, pues el enclave de los cimerios no precede a la entrada al Hades sino a la casa del Sueño. Esta traslación se explica por la asociación existente entre el sueño, la noche y la muerte. Recordemos que ya Hesíodo había usado unos versos sobre la oscuridad semejantes a los aplicados a los cimerios en la Nékyia para describir la morada de Hipnos y Tánatos. Ovidio circunscribe la descripción solo a la morada del Sueño y hace una mención explícita de los cimerios. Para la elaboración de esta morada Ovidio toma detalles de la región homérica y de la cueva descrita en la catábasis de la Eneida. En efecto, Virgilio centra su atención en la cueva por la que el héroe va a acceder al inframundo, de la que emanan unos vapores tan inmundos que ningún ave puede sobrevolar la zona (Aen. VI 237-242). Ovidio, combinando la ambientación homérica y virgiliana, sitúa junto a los cimerios una gruta inaccesible a Febo cuya nociva neblina impide el paso a cualquier animal. Este veto a los animales favorece un silencio absoluto muy adecuado para la residencia del Sueño. En siglos posteriores, cuando el texto homérico sea desconocido, será este pasaje ovidiano el principal transmisor de la existencia de la población mítica.

En el Culex, poema recogido en la Appendix vergiliana y que presenta frecuentes ecos homéricos, un mosquito relata su forzoso descenso al Hades. Al igual que en las Ranas de Aristófanes, la población de los cimerios es trasladada al interior del inframundo. El insecto relata su muerte y, al referir su paso por las regiones de Plutón, afirma que se vio forzado a recorrer «las inaccesibles distancias entre los bosques cimerios» (auia Cimmerios inter distantia lucos, Culex 232). Se trata quizá de la fusión de dos localidades de la Nékyia, el pueblo de los cimerios y el bosque de Perséfone, que en el Culex ya no se sitúan en los alrededores del inframundo sino en su interior.

También Silio Itálico hace referencia al pueblo de los cimerios en sus Púnicas, aunque no durante la experiencia de ultratumba de Escipión, principal muestra del tema en la obra y de claras resonancias homéricas ${ }^{27}$, sino al referir la oportunidad desaprovechada que tuvo Aníbal de acometer una aventura semejante cuando se encontraba en Cumas. Como Licofrón o Antonio Diógenes, Silio Itálico traslada a los cimerios a esta localidad, por donde Eneas inició su catábasis en Eneida VI. Sus guías explican a Aníbal que allí habitan los pobladores homéricos, envueltos en la oscuridad:

${ }^{26}$ Ovidius, Metamorphoses, ed. W. S. Anderson, Leipzig, 1962.

${ }^{27}$ Sobre esta cuestión véase Linares Sánchez 2017, pp. 148-162, con bibliografía. 
at iuxta caligantis longumque per aeuum

infernis pressas nebulis pallente sub umbra

Cimmerias iacuisse domos noctemque profundam

Tartareae narrant urbis.

Sil. Ital XII 130-133

Dicen que cerca, envueltas en la oscuridad y durante largo tiempo

oprimidas por nieblas infernales, bajo la pálida sombra

yacen las moradas cimerias y la profunda noche

de la ciudad del Tártaro. ${ }^{28}$

De esta manera, se pone de relieve que el general cartaginés ha llegado a la entrada del inframundo en la que Odiseo y Eneas acometieron sus aventuras de ultratumba. Al no emular esta arriesgada empresa, como hará Escipión en el libro siguiente, se pone en duda la heroicidad de Aníbal ${ }^{29}$.

En su invectiva contra Rufino el poeta Claudiano (final del S. IV) cita a unos «colonos» que habitan las cercanías de un acceso al Hades en la Galia:

\section{Est locus extremum pandit qua Gallia litus}

Oceani praetentus aquis, ubi fertur Ulixes

sanguine libato populum movisse silentem.

Illic umbrarum tenui stridore volantum

flebilis auditur questus; simulacra coloni

pallida defunctasque vident migrare figuras.

Hinc dea prosiluit Phoebique egressa serenos

infecit radios ululatuque aethera rupit

terrifico.

Ruf. I 123-131

Hay un lugar por el que extiende la Galia su más lejano litoral, situado frente a las aguas del Océano, donde se dice que Ulises, libada la sangre, convocó al pueblo silencioso.

Allí de las sombras que con leve estridor vuelan se escucha el lloroso lamento; los colonos ven pasar las sombras pálidas y los difuntos espectros.

Desde aquí prorrumpió la diosa y al salir cubrió

los serenos rayos de Febo y rompió el aire con un alarido terrorífico. ${ }^{30}$

28 Silius Italicus, La Guerre Punique, Tome III, Livres IX-XIII, ed. y trad. J. VolpilhacLenthéric - M. Martin - P. Miniconi - G. Devallet, Paris, 1984.

${ }^{29}$ Sobre esta cuestión puede leerse Klaassen 2010; van der Keur 2014.

30 Claudian: in two volumes, ed. y trad. M. Platnauer, London / New York, 1922. 
Jorge J. Linares Sánchez

De nuevo se atestigua la existencia de una comunidad humana en el territorio que media entre los vivos y los muertos. Por aquí sale Megera al mundo de los vivos para causar gran discordia, siguiendo el mandato de una asamblea de divinidades infernales. Como sucedía en Los evocadores de espíritus, aunque no se los denomine cimerios, la identificación se hace patente por el contexto del pasaje. Claudiano mantiene el detalle homérico de relacionar a estos «colonos» con las aguas del Océano, donde Homero situaba a los cimerios, y recuerda que en ese mismo lugar realizó Odiseo la nigromancia. También adapta el motivo de la impenetrabilidad al sol del territorio homérico; aquí no se trata de una característica permanente sino del resultado de la salida de Megera desde los infiernos, que cubre los rayos de Febo. Sin embargo, cambia la localización: el poeta latino ubica este territorio en la geografía histórica, en concreto, en «el lugar por el que extiende la Galia su más lejano litoral».

Estos textos nos permiten constatar que la aparición de los cimerios en la Nékyia fue un factor decisivo para que en las recreaciones posteriores del tema se incluyera una comunidad y un enclave humanos vinculados al inframundo. El término para referirse a este pueblo varía de unos textos a otros. En la Nékyia a los habitantes de las cercanías del

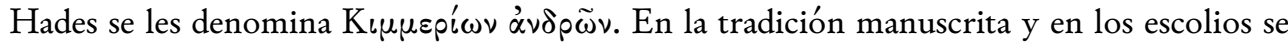
recogen algunas variantes antiguas del nombre de los cimerios (de Aristarco y de Crates,

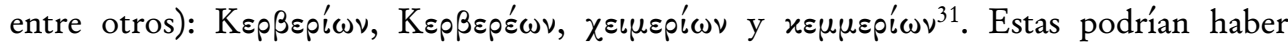
surgido como conjeturas para distinguir a la tribu homérica de la histórica o para dotar al nombre de un significante que remita a otros términos con connotaciones de ultratumba (Kepßépı surgido diversas hipótesis: bien procede de los cimerios históricos (Gimmirai) ${ }^{33}$, bien deriva del cabo Quimerio por el que se accedía al Nekyomanteion de Tesprotia ${ }^{34}$, o es un nombre parlante (neblinosos) ${ }^{35}$.

En los textos analizados solo el resumen de Maravillas increíbles de allende Tule

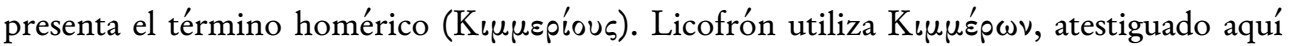
únicamente. En lengua latina encontramos Cimmerios en Ovidio y el Panegírico de Mesala opta por una traslación del genitivo plural griego con Cimmerion. Tanto en el Culex como en las Púnicas se utilizan adjetivos (Cimmerios y Cimmerias). Otros textos, precisamente los situados en los extremos cronológicos del corpus analizado, emplean

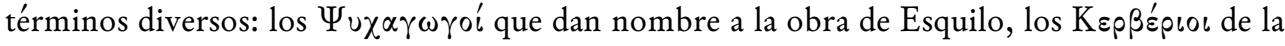
comedia de Aristófanes y los coloni de Claudiano. Esquilo y Aristófanes escriben en una

${ }^{31}$ Cf. Schol. in Od. XI 14; y las ediciones de Ludwich (1889-1891) y West (2017).

32 Heubeck 1988, p. 79; Tsagarakis 2000, p. 40 n. 126. Sobre el empleo de las etimologías alegorizantes en el mundo grecorromano, véase Most 2016.

${ }^{33}$ Véase el amplio estudio sobre este término de Ivantchik (1993, pp. 127-157).

${ }^{34}$ Cf. infra nota 43.

35 Cf., e. g., Bury 1906; Clark 1979, pp. 60-61; Tsagarakis 2000, p. 40; Ogden 2001, pp. 30 y 44. 
época en la que los poemas homéricos constituyen una parte esencial de la cultura y la educación griega. Especialmente en Los evocadores de espíritus, por ser una dramatización homodiegética de la Nékyia, las semejanzas y divergencias respecto a los elementos y personajes homéricos jugarían un importante papel en la recepción de la obra. Es, no obstante, difícil aventurar si el público de estas piezas teatrales captaría todas las

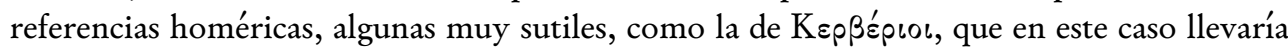
quizás a pensar inmediatamente en el monstruoso can que guarda el Hades. Por su parte, Claudiano facilita la identificación de los colonos con los cimerios al afirmar expresamente que se trata del mismo lugar en el que transcurrió la Nékyia.

No solo la presencia del nombre o la evocación de este pueblo es patente; los pocos detalles que Homero ofrecía sobre el enclave fueron ampliamente retomados y reelaborados en la tradición literaria grecolatina. La mayoría de los autores, siguiendo el pueblo $\left(\delta \tilde{\eta} \mu_{0}\right)$ y la ciudad $\left(\pi_{0} \lambda_{l \varsigma}\right)$ de los cimerios en la Odisea ${ }^{36}$, menciona un lugar edificado y habitado por humanos: los «recintos sagrados» ( $\sigma \eta \eta \hat{\omega} \tilde{\omega} v)$ en Los evocadores de espíritus de Esquilo, las «fincas» ('̌́ $\pi \alpha u \lambda \alpha$ ) en la Alejandra de Licofrón, la «ciudadela fortificada» (arcis) en el «Panegírico a Mesala», las «casas» (domos) en las Púnicas de Silio Itálico o la colonia que se desprende del nombre que les otorga Claudiano (coloni).

Por otro lado, hay una importante tendencia a variar su situación geográfica, lo que se vería favorecido por la ambigüedad del poema homérico acerca de la región en la que se desarrolla la Nékyia. Ya desde antiguo resultaba una cuestión controvertida, que no ha sido resuelta satisfactoriamente. Lo cierto es que el poema ofrece algunos datos sobre la ubicación de la entrada al Hades y de la ciudad de los cimerios (se encontraban en el extremo del Océano, cerca de una playa y del bosque de Perséfone), pero no especifica una localización concreta. Los partidarios de que se trataba de una región fantástica, sin relación con la geografía histórica, difieren acerca de si el poeta los sitúa en el extremo Este u Oeste. Entre quienes defienden una ubicación real, la variedad es aún mayor: Cumas, Enna, Tesprotia, el estrecho de Gibraltar, el Mar Negro, e incluso Egipto han sido propuestos como patria de los cimerios ${ }^{37}$. La ubicación de los cimerios homéricos en la zona del Mar Negro, una de cuyas regiones se denominó Bósforo Cimerio, se debió a la conexión del pueblo mítico con los cimerios históricos. Según fuentes asirias y griegas, como Heródoto o Estrabón ${ }^{38}$, estos cimerios se trasladaron desde el Mar Negro hacia el sur y mantuvieron enfrentamientos con el Imperio Asirio. Posteriormente atravesarían la península de Anatolia y atacarían las ciudades helenas de Asia Menor ${ }^{39}$. El poeta Calino

\footnotetext{
${ }^{36}$ Esta fórmula aparece en otros pasajes de la Odisea. En Od. VI 3 designa al pueblo y ciudad

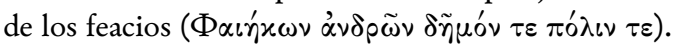

37 Cf. Norman 2016; y en especial Burgess 2016, que repasa los diversos intentos antiguos y modernos de localizar geográficamente la Nékyia.

${ }^{38}$ Hdt. I 6, 15-16, 103 y IV 11-12; Str. I 3. 21, XI 2. 5.

${ }^{39}$ Ivantchik 1993 y Bridgman 1998 analizan la información que tenemos acerca de los cimerios históricos.
} 
Jorge J. Linares Sánchez

(S. VII a. C.) habría vivido estas luchas de primera mano, pues los presenta como una violenta amenaza ${ }^{40}$. Pero antes de su migración a Asia Menor, los griegos habrían tenido noticias de ellos. Algunos investigadores, en su defensa de la conexión entre los cimerios míticos y los históricos, consideran que Homero tomó el nombre de un poema anterior sobre la travesía de los Argonautas por el Mar Negro en el que se citaba a los cimerios ${ }^{41}$. Esta zona, en particular el Bósforo Cimerio, se consideraba el extremo del mundo y, en consecuencia, se identificó con el inframundo ${ }^{42}$.

En efecto, debido a la ambientación de ultratumba de la Nékyia, las regiones en las que se ha considerado que transcurriría el episodio, y, por tanto, el lugar en el que Homero habría localizado a los cimerios, suelen tener una marcada tradición ctónica. Pausanias (I 17. 5), por ejemplo, consideraba que el poeta griego había ambientado el episodio basándose en la región de Tesprotia, donde se había erigido un Nekyomanteion y por donde fluía el río Aqueronte ${ }^{43}$. Estrabón (V 4. 5), por su parte, afirmaba que Odiseo había visitado un santuario junto al lago Averno, cerca de Cumas, donde existía un oráculo de los muertos. Escribe Estrabón, siguiendo a Éforo, que los cimerios habitaban aquí unas moradas subterráneas y recibían a los extranjeros que acudían al oráculo, también bajo tierra. Tenían prohibido ver la luz del sol, de ahí que Homero dijera que Helios nunca los ilumina con sus rayos. Estas últimas hipótesis, Tesprotia y Cumas, han sido las más seguidas para la ubicación de la Nékyia en el poema homérico, tanto entre los antiguos como entre los modernos.

Estas divergencias acerca del emplazamiento de la Nékyia favorecieron que en los textos posteriores sobre el viaje al más allá el pueblo de los cimerios se ubicara con facilidad en diferentes lugares de características similares a las descritas en Odisea XI. Por lo general, dada la temática del episodio, se opta por una localización de naturaleza ctónica. Es más, la ambientación de ultratumba de la ciudad cimeria facilitó incluso que en ocasiones fuera introducida directamente en el inframundo, por lo que se convirtió en

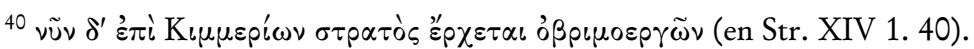

${ }^{41}$ Ivantchik 2005, p. 88; West 2005, pp. 54-56. Sobre la relación entre el nombre de los cimerios míticos y los históricos existen teorías dispares: que Homero tomó el nombre de los cimerios históricos, que en aquella época serían poco más que una noción exótica para los griegos; que estos denominaron posteriormente cimerios al pueblo histórico por influencia del poema homérico; o que se trata de una coincidencia fortuita. Cf. Heubeck 1988, pp. 77-79.

${ }^{42}$ Ivantchik postula incluso que existiría una versión primitiva y no homérica de la Nékyia que tendría lugar en el Mar Negro (2005, p. 93). Por otro lado, la isla de Leuce, lugar mítico de bienaventuranza al que según la tradición fue llevado Aquiles, se identificó con la actual Isla de las Serpientes, también en el Mar Negro, donde se desarrolló un importante culto local del héroe ( $c f$. Oller Guzmán 2014 y las referencias bibliográficas que ofrece, en especial Hedreen, Hommel y Hooker). Como vemos, esta zona tuvo para los griegos una intensa connotación escatológica.

${ }^{43}$ En esta zona, según Tucídides (I 30.3 y 46. 3), se encontraba el cabo Quimerio (Xeıนépıov).

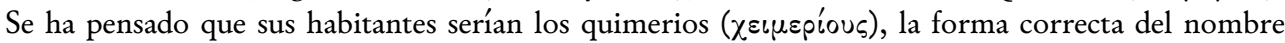
de los cimerios según Proteas Zeugmatites (EM 513. 50). 
una nueva zona del más allá (Ranas y Culex). Entre los autores que optan por la localización real abundan quienes los sitúan en Cumas, donde ciertos eruditos consideraron que transcurría la Nékyia. Ya Licofrón en su recreación de las aventuras de Homero localiza aquí la evocación homérica. Es muy probable que el prestigio de la Eneida, cuyo héroe también descendió a los infiernos en Cumas, tuviera cierta influencia en que autores posteriores, como Silio Itálico, optaran por esta alternativa.

En estos pasajes se aplican con frecuencia a los cimerios las principales características de las inmediaciones del inframundo, la niebla y la oscuridad, con la especificación homérica de que esta se ha originado por la impenetrabilidad del enclave a los rayos del sol, tanto al alba como al ocaso. Además, siguiendo a Homero, en la mayoría de los textos el protagonista no entra en contacto con ellos, que conservan su aura misteriosa e inescrutable, por lo que no participan en la acción y quedan como parte de la ambientación del más allá. Las únicas excepciones son Los evocadores de espíritus de Esquilo y Maravillas increíbles de allende Tule de Antonio Diógenes. En la primera obra, al pertenecer al género dramático, se optó por convertirlos en el coro de la tragedia, como los nigromantes encargados de dar al héroe las instrucciones sobre la evocación. Por tanto, su participación y presencia debió ser muy destacada. También debieron de tener un importante papel en la experiencia de ultratumba de Derć́lide. Focio afirma que la heroína se dirigió a ellos, en la zona de Cumas, y allí vio las cosas del Hades, por lo que es razonable pensar que entró en contacto con la mítica población. Sin embargo, el encargo de explicar los entresijos del inframundo no recae en los cimerios, sino en un difunto, Mirto, antigua sirviente de la joven. El resumen de Focio no nos ofrece más indicaciones. Respecto a esta cuestión, Ogden considera que la descripción que realizó Estrabón de los cimerios como encargados de un oráculo de los muertos en Cumas sirvió de inspiración a Antonio Diógenes ${ }^{44}$. Si esto es así, y a tenor de la función que los cimerios tenían en la obra de Esquilo, el único texto en el que tienen una participación activa, se puede conjeturar que en la novela griega los cimerios tomarían parte, quizás dando las prescripciones oportunas, en el ritual de evocación mediante el cual se invocó al espíritu de Mirto.

En estas páginas hemos podido constatar que la innovadora descripción que Homero hace de los cimerios como habitantes de una ciudad vinculada al inframundo se incorporó a la tradición literaria grecolatina del viaje al mundo de los muertos. Desde entonces, el pueblo de los cimerios quedó constituido como un elemento característico del lugar de evocación o catábasis. Los autores comentados han reelaborado el texto homérico, adaptándolo a las necesidades narrativas y a las características de sus obras. De esta manera, la presencia de los cimerios en los textos posteriores refuerza la conexión de la nueva aventura con el viaje al más allá de Odiseo, lo que le otorga la fuerza y el prestigio de la tradición homérica.

\footnotetext{
${ }^{44}$ Cf. Ogden 2014, p. 216.
} 
Jorge J. Linares Sánchez

\section{BIBLIOGRAFIA}

A. M. BAERTSCHI, 2013, Nekyiai. Totenbeschwörung und Unterweltsbegegnung im neronischflavischen Epos, Berlin.

T. BRIDGMAN, 1998, "Who were the Cimmerians?", Hermathena 164, pp. 31-64.

M. BRIOSO SÁNCHEZ, 2002, "El motivo del viaje en Las historias increíbles de más allá de Tule de Antonio Diógenes", Fortunatae 13, pp. 65-87.

J. S. BURGESS, 2016, "Localization of the Odyssey's Underworld", CEA 53, pp. 15-37.

J. B. BURY, 1906, "The Homeric and the Historic Kimmerians", Klio 6, pp. 77-88.

R. J. ClaRK, 1979, Catabasis: Vergil and the Wisdom-Tradition, Amsterdam.

C. COUSIN, 2005, "La Nékyia homérique et les fragments des Évocateurs d'âmes d'Eschyle", Gaia 9, pp. 137-152.

E. FRENZEL, 1980, Diccionario de motivos de la Literatura Universal, trad. M. Albella Martín, Madrid.

J. GARCÍA LóPEZ, 1993, Aristófanes. Las Ranas. Introducción, comentario y traducción, Murcia.

A. R. GeORGE (ed.), 2003, The Babylonian Gilgamesh Epic. Introduction, Critical Edition and Cuneiform Texts, 2 vols., Oxford.

A. HeUBECK, 1988, "Books IX-XII", en A. Heubeck - A. Hoekstra, A Commentary on Homer's "Odyssey”. Volume II. Books IX-XVI, Oxford, pp. 1-143.

U. HÖLSCHER, 1991, L'Odissea. Epos tra fiaba e romanzo, trad. F. Stella, Firenze.

A. I. IVANTCHIK, 1993, Les Cimmériens au Proche-Orient (OBO 127), Fribourg Göttingen.

A. I. IVANTCHIK, 2005, "Le dêmos et la polis des Cimmériens dans l'Odyssée (XI, 14): le contenu de l'image épique", en D. Kacharava - M. Faudot - E. Geny (eds.), Pont-Euxin et polis, (Actes du Xe Symposium de Vani), Besançon, pp. 83-98.

H. JUHNKE, 1972, Homerisches in römischer Epik flavischer Zeit, München.

E. K. KlaAsSen, 2010, "Imitation and the Hero", en A. Augoustakis (ed.), Brill's Companion to Silius Italicus, Leiden, pp. 99-126.

F. LARA PeINADO, 2002, Leyendas de la Antigua Mesopotamia: Dioses, héroes y seres fantásticos, Madrid.

J. J. LINARES SÁNCHEZ, 2017, El tema del viaje al mundo de los muertos en la Odisea y su tradición en la literatura occidental (Tesis Doctoral), Murcia.

J. M. LUCAS DE DIOS, 2008, Esquilo: Fragmentos. Testimonios, Madrid.

S. M. MACÍAS OTERO, 2015, "On the Threshold of Hades: Necromancy and Nékyia in some Passages of Greek Tragedy”, LEC 83, pp. 137-153.

K. MATIJEVIĆ, 2015, Ursprung und Charakter der homerischen Jenseitsvorstellungen, Paderborn.

K. MiKellidOU, 2016, "Aeschylus reading Homer: the Case of the Psychagogoi", en A. Efstathiou - I. Karamanou (eds.), Homeric Receptions across Generic and Cultural Contexts, Berlin - Boston, pp. 331-341. 
G. W. MOST, 2016, “Allegoresis and Etymology”, en A. Grafton - G. W. Most (eds.), Canonical Texts and Scholarly Practices: A Global Comparative Approach, Cambridge, pp. 52-74.

B. NORMAN, 2016, "Re-assessing the Location of the Homeric Underworld in the Odyssey Book XI", International Journal of Student Research in Archaeology 1.1, pp. 1-14.

D. OGDEN, 2001, Greek and Roman Necromancy, Princeton.

D. OGDEN, 2014, "How 'Western' were the Ancient Oracles of the Dead?", en L. Breglia - A. Moleti (eds.), Hespería: Tradizioni, Rotte, Paesaggi, Paestum, pp. 211-226.

M. OlLER GUZMÁN, 2014, "Fantasmas de Aquiles: epifanías heroicas entre el mito y el culto", Minerva 27, pp. 77-96.

S. PONCHIA, 2002, "Odisseo e Gilgamesh: viaggi a confronto", en L. de Finis - V. Citti - L. Belloni (eds.), Odisseo dal Mediterraneo all'Europa, Amsterdam, pp. 9-21.

V. PROPP, 1979, Las raíces históricas del cuento, trad. J. Martín Arancibia, Madrid.

M. A. Santamaría Álvarez, 2015, "The Parody of the Katábasis-Motif in Aristophanes' Frogs", LEC 83, p. 117-136.

S. THOMPSON, 1955, Motif-Index of Folk-Literature, vol. III: F-H, Indianapolis.

O. TSAGARAKIS, 2000, Studies in Odyssey 11, Stuttgart.

M. VAN DER KeUR, 2014, “Meruit deus esse videtur: Silius' Homer in Homer's Punica 13”, en A. Augoustakis (ed.), Flavian Poetry and its Greek Past, Leiden, pp. 287-304.

T. B. L. WEBSTER, 1958, From Mycenae to Homer, London.

M. L. West, 2003 [1997], The East Face of Helicon: West Asiatic Elements in Greek Poetry and Myth, Oxford.

M. L. WeST, 2005, “Odyssey and Argonautica”, CQ 55.1, pp. 39-64.

M. L. WEST, 2014, The Making of the Odyssey, Oxford. 